\title{
Education-Welfare for Immigrant Children: How Schools are Involved in the Daily Lives of Immigrants
}

\author{
Tori Homma*
}

\begin{abstract}
The purpose of this study is to analyze how immigrant children in Japan are included in the phenomenon of gakko kino no fukushika (Kuraishi 2014: 56) - henceforth "welfare-oriented schools"-by using the analytical framework of education-welfare. Fieldwork took place in an elementary school Japanese language class, along with interviews with immigrant mothers, a Japanese language teacher and a Filipino language supporter. The paper focused on three aspects of Filipino immigrants' lives: child neglect, dietary habits, and truancy. As regards education-welfare, this study has illustrated both the possibilities and limitations of teachers taking the "care" roles for immigrant children. Although previous literature has drawn a distinctive line between education and welfare specialists, in this study, the boundary was ambiguous as the Japanese language teacher considered herself a "social worker." On the other hand, one of the limitations was that the teachers" dominant ideology of a "good" way of living excluded the logic of the immigrants.
\end{abstract}

Keywords: education-welfare; welfare-oriented school; immigrants; Japanese language class; qualitative research

\section{Introduction}

The purpose of this study is to analyze how immigrant children in Japan are included in the phenomenon of gakko kino no fukushika (Kuraishi 2014: 56) — henceforth "welfare-oriented school" - as translated by the author. This term denotes the extended roles played by schools as institutions not only of education but also of welfare (Kuraishi 2014: 56). Over the last few years, every child has been exposed to an environment where there is poverty, depression, bullying, truancy, abuse, an increasing need for special education, and so on.

\footnotetext{
* Graduate School of Kyoto University, Human and Environmental Studies. Research Fellow of Japan Society for the Promotion of Science. e-mail: tori.homma@gmail.com
} 
Consequently, "schools have had no choice but to actively be involved in the spheres of welfare" (Kuraishi 2018:40). This phenomenon has been followed by governmental policies such as introducing social workers at schools in 2008, the promotion of "schools as a platform of poverty alleviation," and the mandatory reporting of child abuse (Kuraishi 2018: 39).

As regards the growing number of immigrant children in Japan, educational researchers have mostly focused on discussing how to secure education for them. Some have pointed out that the exclusive nature of Japanese school culture makes immigrant children feel isolated and uncomfortable at school, leading to truancy and dropouts (e.g. Shimizu 2008). In addition, previous research has demonstrated that immigrant children have less access to education due to their lack of Japanese language skills, their age upon arrival, socioeconomic hardship, and resident status (e.g. Kojima 2016). The low rate of high school enrollment of immigrant children due to selection and inadequate resources and support system has also been raised as an issue to take into consideration (e.g. Kaji 2007).

However, discussing how to secure education for immigrant children is not sufficient. As immigrant children are also part of the complicated phenomenon of the "welfare-oriented school," it is necessary to depict its internal realities and to examine how immigrant families are included in the education-welfare framework. This study illustrates how teachers become involved in the daily lives of immigrant families and how immigrant families respond to such intervention. Thus, it is meant to contribute to the discussion on education-welfare for families with diverse cultural backgrounds.

\section{Background of Filipino Immigrant Children in Japan}

This study is specifically focused on Filipino immigrant children and their mothers in Japan, since statistics and previous studies show that they are at great economic and social disadvantage.

Firstly, the Filipino immigrant community in Japan is characterized by a large number of single-mother households. Filipinos are the fourth largest immigrant population in the country, with a total of 292,649 people (Ministry of Justice 2020). Women represent almost $70.0 \%$, most of whom are permanent $(45.3 \%)$ or long-term residents (18.4\%) (MOJ 2020). According to a survey by the Ministry of Health, Labour and Welfare (2018a), Filipino residents are by nationality the second most numerous recipients of public assistance among non-Japanese, comprising $11.6 \%$ of the total foreign recipients. Furthermore, $59.8 \%$ of the Filipino households that receive public assistance are single-mother households. Considering that single-mother households only comprise $5.6 \%$ of the total recipients of public assistance, this large number is distinctive. The explanation for this situation can be found in the historical background of Filipino immigration to Japan.

In the light of globalization and economic growth, the Japanese government started to accept young Filipino women to the country as entertainers in pubs at the beginning of the 1980s. Until the United States warned Japan that such activities were regarded as human trafficking and the so-called "entertainer visa" (kogyo visa) was regulated in 2005, more than one million Filipino entertainers came to Japan (Hara 2018). Consequently, the number of marriages between Japanese men and Filipino women from 1992 to 2004 ranged from 5,000 to 8,000 per year. Moreover, these numbers increased to over 10,000 after the regulation of 
the visa in 2005, with more Filipino women using marriage to local men as a means to stay in the country (MHLW 2018b).

Notwithstanding this cross-cultural marriage boom, in some cases Japanese-Filipino children were born after their mothers went back to the Philippines, or out of wedlock. Due to the revision of the Japanese Nationality Act in 2008, it has become possible for these children to acquire Japanese nationality if recognized by their Japanese father before the age of 20. Consequently, many Filipino mothers - including former entertainers - have come back to Japan with the help of NPOs or brokers, seeking the recognition of their children. This explains the large number of single-mother households among Filipino immigrants in Japan.

Another marker of the economic and social disadvantage of Filipino mothers in Japan is that while local women work in various sectors, Filipino women are mostly so-called blue-collar workers. According to the Japanese national census of 2015, 43.5\% of Filipino immigrant women worked in the manufacturing sector, $19.5 \%$ in the service sector, and $13.9 \%$ in the transportation, cleaning, and packaging sector (Ministry of Internal Affairs and Communications 2017). Consequently, they are more likely to lose their jobs in the case of an economic downturn. In fact, the COVID-19 crisis has severely affected Filipino residents in Japan, especially those marriage migrants who worked as part-timers (Asato 2020). It is estimated that the average monthly income of Filipino residents decreased from 136,900 yen to 62,500 yen by June 2020 due to the pandemic (Asato 2020).

Considering all of the above, investigating how Filipino children and mothers are included in the "welfare-oriented school" is crucial.

\section{Education-Welfare as an Analytical Framework}

As the word "welfare-oriented school" implies, schools are compelled to become involved in the sphere of welfare. However, the two pioneering "welfare-oriented school" examples introduced in this section have demonstrated the difficulties of connecting the logic of education and the logic of welfare.

The first example is the pastoral system of the United Kingdom. In the UK, after grammar, technical, and secondary modern schools were combined into comprehensive schools in 1965, teachers had to deal with the diverse needs of their students. As a result, the so-called "pastoral system" was established, changing teachers' perceptions of their students (Johnson et al. $1980=1983$ ). They were called on to care not only about students' academic success, but also about their social and emotional condition. Furthermore, teachers tried to understand students as individuals by getting to know their family lives and the issues they confronted outside school (Johnson et al. 1980=1983). However, teachers within this system started to face some dilemmas. One concern was whether pastoral care could be conducted alongside discipline in order to manage the school and classes (Johnson et al. 1980=1983). Another issue was teachers' expertise. It was widely pointed out that demanding that schools pay more attention to the welfare sector could threaten schools' professionalism as educational institutions and teachers' expertise in education (Johnson et al. 1980=1983).

Another example of teachers getting involved in the daily lives of their students is the fukushi kyoin, "welfare educators dealing with non-attendant and truant students from the buraku outcaste communities in Kochi Prefecture" in the 1950s (Kuraishi 2015:582). Teachers 
regarded as fukushi kyoin expressed in their reports the internal conflicts they went through. For instance, when buraku children had to work for a living, the fukushi kyoin found it hard to force them to attend school. The inclusion of these children in education was not leading directly to an improvement of their daily lives (Kuraishi 2015, 2018).

There are also theoretical discussions on the difficulties of connecting the logic of education and welfare in the research field of education-welfare. As an example, Takada (2019) claims that the collaboration of specialists in education and in welfare is difficult, since their approaches to children are different. While the former deal with issues such as poverty and social exclusion in order to achieve effective education, the latter perceive education as part of realizing children's well-being (Takada 2019). In addition, Nihei (2018) points out that the logic of education denies the unconditional right to life security by showing how citizenship education values "independent" citizens. Yamaguchi and Tsutsumi (2014) also criticize how the logic of education produces social inequality by selecting and excluding certain groups of people: it justifies social security policies that guarantee rights only under specific conditions. Furthermore, practitioners of social work at schools indicate that the institution's attempts to maintain group harmony can conflict with the needs of individual families (Japanese Society for the Study of School Social Work 2008).

Consequently, the coexistence of the logic of education and welfare within the "welfare-oriented school" is still controversial and requires further discussion.

\section{Methodology}

In order to examine how immigrant families are included in the framework of education-welfare and what kind of conflicts have arisen among different actors within the "welfare-oriented school," I conducted fieldwork and interviews.

I did fieldwork at an afterschool Japanese language class at the public Y Elementary School in X City from May 2018 to December 2019. The X City Board of Education has had support measures for immigrant children since 2014. Under these support measures, children who have been in Japan for less than a year can take private Japanese language classes as part of their official curriculum during school hours. Those who need special support can also participate in Japanese language classes after school. Furthermore, Japanese language teachers and bogo-shien'in, language supporters who speak immigrant children's native languages, visit multiple schools to assist them.

Y Elementary School is in an area where Filipino immigrants, as well as economicallydisadvantaged households, are concentrated. I found Y School to be a good example of a "welfare-oriented school," as the Japanese language teacher and the language supporter were actively involved in the daily lives of the immigrant children. They frequently visited the children's homes and tried to understand their financial, immigration status, and family situations. Although a social worker has visited Y Elementary School once a week since 2018 according to X City policy, the Japanese language teacher claimed that what the social worker could do was very limited as the she did not have a chance to interact with immigrant children directly on a daily basis, and did not know much about immigration policies (Interview July 31, 2019). The conditions of school social workers vary depending on the cities; while some cities allocate social workers to each school, other cities have social workers visit mul- 
tiple schools. X City takes the latter policy, in which a social worker visits multiple schools.

I participated at Y Elementary School as a student volunteer in its afterschool Japanese language classes once or twice a week for about ninety minutes a day, assisting immigrant children with their homework. There were about 7 children from the Philippines in the classes. The fieldwork at the Japanese language classes was appropriate for this study because these classes are the "only place where immigrant children can freely express their cultural backgrounds" (Ota 2000: 211). Thus, I could observe the interactions between teachers and immigrant children more closely than in regular classes.

Moreover, in order to understand what happens within the "welfare-oriented school" from different perspectives, interviews were conducted with Filipino immigrant mothers, a Japanese language teacher and a Filipino language supporter at Y Elementary School.

In this paper, I have selected three cases of Filipino families recognized by teachers as "needing support" in order to discuss the impact of education-welfare on their lives. Table 1 presents the children's profiles and Table 2 shows those of their mothers. All mothers in this study worked as caregivers after having received a three-month training in the Philippines. They all hold long-term visa status. Moreover, Katy and Mary were single mothers whose children's fathers were Japanese nationals.

Table 1 Children's Profiles

\begin{tabular}{|l|l|l|l|l|}
\hline \multicolumn{1}{|c|}{ Name } & \multicolumn{1}{|c|}{ Mother } & \multicolumn{1}{c|}{ Grade } & \multicolumn{1}{c|}{ Age of Arrival } & \multicolumn{1}{c|}{ Nationality } \\
\hline Manami & Katy & First grade & 5 years old & Philippines \\
\hline Saki & Mary & First grade & 5 years old & Philippines \\
\hline Mirei & Maya & Third grade & 1 year old & Philippines, Japan \\
\hline
\end{tabular}

Table 2 Mother's Profiles

\begin{tabular}{|l|l|l|l|l|l|}
\hline \multicolumn{1}{|c|}{ Name } & \multicolumn{1}{c|}{ Hometown } & \multicolumn{1}{c|}{ Language } & \multicolumn{1}{c|}{ Religion } & \multicolumn{1}{c|}{ Year of Arrival } & \multicolumn{1}{c|}{ VISA } \\
\hline Katy & Metro Manila & Tagalog & Catholic & 2016 & Long term \\
\hline Mary & Samar Island & Tagalog & Iglesia & 2016 & Long term \\
\hline Maya & Pangasinan & Tagalog & Iglesia & 2011 & Long term \\
\hline
\end{tabular}

The Japanese language teacher has been working at Y Elementary School since 2009. She is in charge of the Japanese language classes for immigrant children, the multicultural lessons, and the training of new Japanese language teachers. The Filipino language supporter has been working at the school since 2015. She came to Japan in the 1980s and has been one of the most active members of the Filipino community in X City. When this study was carried out, she was visiting four schools as a supporter.

$\mathrm{X}$ City was an appropriate city for this study, since it has a long history of striving to integrate education and welfare. In addition, the total number of foreign residents in the city, including those of Filipino origin, is rapidly increasing. Thus, examining the impact of school welfare on diverse population groups is an urgent issue.

Regarding ethical considerations, I received consent to participate in this study from all of my interviewees. As the study addresses family privacy issues, I also received consent from the principal of Y Elementary School. 


\section{5. "Welfare-oriented school” for Immigrant Children}

\section{5-1. Child neglect}

Jessica: "My room is messy because of Manami. She sleeps in my room and I even have to take showers with her. I'm tired of it."

Japanese language teacher: "I see. Manami is staying at your apartment."

(June 25, 2018 at Japanese language class)

During my stay at Y Elementary School, I could observe how the Japanese language classes offered teachers an important opportunity to understand the daily lives of immigrant children. Through their conversations during the class, the Japanese language teacher found out that Jessica, a fifth-grade Filipina student, was taking care of Manami at home. From the perspective of the Japanese language teacher and the classroom teacher, Manami's mother Katy was not taking good care of her. She had not treated Manami's skin when she had a skin problem, she was not checking her homework, and she had not read the messages from the school. Also, when the classroom teacher had visited Manami's apartment, she had noticed that there was only one room in the apartment, with two-thirds of it taken up by a giant bed. There was no desk for studying, this being one of the reasons why Manami could not study at home. Furthermore, the Filipino language supporter had found out through social media that Katy was partying at night, leaving her children alone at home. Based on this evidence, the teachers had come to think that Katy was not taking proper care of Manami.

Japanese language teacher: "Even if I want to teach Japanese, it is impossible for little children to concentrate when their home environment is not good. Consequently, I have to become a social worker."

(Interview, July 31, 2019)

The Japanese language teacher believed that the home environment had a significant impact on the motivation and academic achievement of the children. As she felt that not only Manami but also Katy needed support, she tried to contact Katy frequently. When the teachers wanted to make sure Manami was safe, they also contacted Katy's workplace if they could not reach her on her cellphone. Moreover, with the help of the Filipino language supporter, the teachers kept collecting information about Katy and attempted to prevent any problems from happening.

Although the teachers expressed concerns about Katy's performance as Manami's mother, Katy believed that she was doing her best in taking care of her children.

Katy: "There is no stress in the Philippines. I have no family in Japan. I do everything by myself. In general, people have a boyfriend, a husband, and family. I'm jealous sometimes, but I'm happy. No one helps me and I'm proud."

(Interview, February 11, 2019)

Katy emphasized during our interview that she was doing everything by herself as a single mother. Any support that the teachers were trying to provide for Manami and Katy was 
not being regarded as "support" by Katy herself. She sometimes felt that the teachers were scolding her even though she was waking up early every day, cooking breakfast, checking school materials, and reading messages from school through a translator for Manami. Furthermore, she wanted Manami to be as "independent" as possible so that she could have a "better life." Therefore, she was letting Manami do what she could: for instance, she was letting the child do the laundry and her homework alone. However, Katy's efforts and beliefs were not visible to the teachers.

\section{5-2. Dietary habits and delinquency}

Saki's diet started at the end of 2018, after her homeroom teacher persuaded her and Mary, her mother, to change their dietary habits. The homeroom teacher had also connected them to a doctor.

Mary: “The homeroom teacher said, 'Saki is too fat. She had better be hospitalized.' I was so stressed."

(Interview, January 30, 2019)

Although stressed, Saki and Mary worked on changing their dietary habits. They promised to go to check-ups at a hospital once a month with the Filipino language supporter and to report the results to the school. Moreover, every Friday, Saki had to visit the nurse's room at school in order to be weighed. Mary bought a weight scale for their home, reduced the amount of rice in their meals, and started jogging with Saki. However, during the spring break, Mary did not take Saki to the hospital and Saki gained $2 \mathrm{~kg}$. The teachers were frustrated with Mary, feeling that she did not care about Saki's health. On the other hand, the Filipino language supporter had sensed that Saki and Mary had been under too much pressure.

In June, the teachers became increasingly concerned about Saki's attitude, as she had started to go out at night without Mary's permission. On one of these occasions, she was caught by her mother at the convenience store. Saki had stolen Mary's money and bought some snacks. Another night, Saki was caught by a school friend's parent because she was riding her classmate's bicycle without permission. Mary was not able to find Saki that night because she did not know who Saki's friends were. This issue became a big problem at school.

Japanese language teacher: "This is common among immigrant families. Saki does not respect her mother because she can read, write, and speak Japanese better. We should do something before the parent-child relationship gets worse."

(June 21, 2019 at Japanese language class)

The Japanese language teacher suggested that Mary study Japanese so that Saki would not disdain her. She believed that language is not just a convenient tool, but can also build parent-child relationships. The Japanese language teacher also told Mary that she could provide her with information on Saki's friends so that Mary could ask them for help if Saki disappeared again.

In July, Saki was suddenly admitted to a hospital for a month. According to the Japa- 
nese language teacher, it was not just a matter of Saki's weight. The teachers considered it to be a positive measure for several reasons. Firstly, while Saki was in the hospital, there was no need to worry about Saki running away at night. Secondly, Mary could distance herself from Saki and rest for a while. Thirdly, Saki could learn "the right amount of food in a meal." Fourthly, Saki could work on her homework at the hospital. However, the Filipino language supporter had a different perspective. She believed that Mary and Saki had been stressed by the involvement of the school in their daily life.

Filipino language supporter: "When I visited Mary's house with the teachers, Saki was cooking alone. I was impressed that Saki could help her mother, but not one teacher took it positively."

(Interview, September 3, 2019)

The teachers were worried that Saki could not control the amount of rice she was eating if she cooked by herself. The Filipino language supporter explained that in the Philippines children help their families with cooking and that child obesity is not considered to be an issue. Furthermore, while Saki's teachers thought that she was "problematic," within the Filipino community, she was popular among adults because she could speak to them politely. All in all, although teachers had no doubt that Saki needed to change her diet and attitude, Saki and Mary did not think the same way.

\section{5-3. Truancy}

Mirei had been absent from school since September 2018, for about six months. Mirei had told the Japanese language teacher that she had no more friends at school after Jessica, a good friend of hers, was suddenly deported to the Philippines. Mirei had also said that she missed the Philippines, where many of her family members lived. In contrast, she only had two siblings living in Japan. The Japanese language teacher felt that Mirei could not attend school due to psychological shock and accumulation of loneliness. Therefore, she asked Maya, Mirei's mother, to be with the child as much as possible. However, Maya told the teachers that she could not be absent from work. Because of the way she replied, the teachers thought that Maya was not taking the issue seriously.

The classroom teacher, the Japanese language teacher, the Filipino language supporter, the school counselor, and Maya held meetings regularly. According to the Filipino language supporter, Maya had gotten very emotional at one of the meetings.

Filipino language supporter: "She said, 'Japanese people do not understand Filipino culture.' She probably wanted me to take her side. She was furious. I also cried that day on the way home."

(November 2, 2018 at Japanese language class)

When this meeting took place, Mirei had not gone to school in about two months. Maya suggested giving Mirei pocket money if she went to school as a means to motivate her. When the teachers strongly disagreed with the idea, thinking that it would not help Mirei, Maya sought the approval of the Filipino language supporter by saying that it was a common 
practice in the Philippines. The Filipino language supporter suffered at the time, as she could not agree with Maya.

One month later, Mirei's mother told me in our interview that she wanted to communicate more with the teachers (December 28, 2018). She believed that the misunderstandings between her and the teachers in their daily lives could be one of the reasons why Mirei did not want to go to school. For example, Maya was taking her children to church late at night, but the teachers had requested her to let them go to sleep earlier as they were often late for school in the mornings and unable to concentrate in class. However, attending church was Maya's priority.

\section{Discussion}

\section{6-1. Can teachers be welfare specialists?}

As regards education-welfare, this study has illustrated both the possibilities and limitations of teachers taking the role of welfare specialists for immigrant children. The Japanese language teacher and the Filipino language supporter were involved in the daily lives of Filipino children in a variety of ways. They were trying to understand how these children spent their time at home by observing their attitudes and conversations at school. Even during holidays, they visited the families whom they were concerned about. When they could not contact immigrant mothers, they contacted mothers' workplace to check if the children were safe. They had frequently reached out to immigrant mothers and helped them with important procedures such as going to the hospital and applying for child-rearing allowances or visas. When there was suspicion of child neglect, dietary problems, or truancy, it was also the Japanese language teacher and the Filipino language supporter who took the lead in solving the issues.

In the case of Y Elementary School, the cooperation of the Filipino language supporter was essential for the involvement of the school in the daily lives of immigrant families. As a member of the Filipino community, she could discover private information about the immigrant mothers, which made the school's involvement smoother. For example, the teachers discovered that Katy was frequently absent from home after the Filipino language supporter collected evidence from within the immigrant community. On another occasion, the teachers had received information beforehand from the language supporter which had prevented an immigrant mother and her children from disappearing without warning. In addition, the Filipino language supporter had made it possible for the teachers to understand the logic of immigrant families.

As these examples show, it is possible for teachers to take the role of welfare specialists. Previous literature has drawn a distinctive line between education and welfare specialists, arguing that they understand children differently (e.g. Takada 2019); however, in this study, the boundary was ambiguous. Although not confident about her expertise as a teacher and distressed from time to time, the Japanese language teacher created a new identity by positioning language as an essential tool for supporting the daily lives of immigrants. Because she had more experience dealing with immigrant families than any other staff member at school as well as more knowledge about visa status, patterns of parent-child relationships among immigrants, and the hardships they confront, it seemed more effective for her to act 
as a "social worker."

Nonetheless, when I asked the Japanese language teacher if she had any requests regarding the current system, she did not hesitate to answer, "I want more staff who can do social work at school" (Interview, July 31, 2019). The Japanese language teacher had felt some limitations when taking a "care role" with the immigrant families. Firstly, as social work takes a lot of her time, she expressed the desire to have more time to prepare her language classes as a professional in education. This complaint supports Johnson et al. (1980=1983)'s discussion on teachers' expertise. Secondly, it was difficult for the language teacher to take the children's side because teachers are expected to educate their students in what is "good" and "bad," and encourage them to "learn" and "develop." While yorisoi, or standing by others, is said to be a key concept in social work (Ikai 2016), it was not always easy for the language teacher. As explained more in detail in 6-2, the majority-minority relationship made the logic of the teachers especially demanding towards the Filipino immigrant families.

\section{6-2. The Dominant Ideology behind "Welfare"}

This study has revealed that it is even more difficult than expected for teachers to be involved in the daily lives of immigrant families, as majority-minority relationships are also at work. In the phenomenon of the "welfare-oriented school," there is a dominant ideology of what makes a "good" way of living. How immigrant children and their mothers perceive their way of living has been obscured within the school setting. In other words, they have often struggled because of the school's involvement in their family life in the name of welfare.

In this study, the teachers required Filipino mothers to take care of their children "appropriately" by letting their children maintain an "appropriate" weight, wear "appropriate" clothes, and lead a "regulated" life. However, what these immigrant families thought to be an "appropriate" life was not necessarily the same as the teachers" own perceptions. Mary had let Saki eat a lot of rice despite her teachers' concerns about her obesity. Katy was trying to let Manami be "independent," something that her teachers considered child neglect.

When the logic of teachers and immigrant families conflicted, the Filipino language supporter complained that she was "a cheese between the burgers" (Interview, September 3, 2019), and often had to face the difficulty of juggling teachers and the Filipino community. While the teachers expected her to obtain information on Filipino mothers from within the Filipino community, the mothers expected her to understand their "culture," as Maya's example shows. As regards the Filipino children, many of them saw the language supporter as someone with whom they could express themselves but simultaneously as the one who could disclose problematic information about them to mothers and teachers. For instance, Manami was afraid that her mother would find out that she was not doing her homework because the Filipino language supporter had translated a complaint letter from a classroom teacher into Tagalog. Therefore, in the school setting, even the supporter confronted difficulties when taking "care" roles with the immigrant families.

In fact, the teachers were conscious of majority-minority relationships. The Japanese language teacher mentioned that it is essential for teachers to be careful how they talk and to build trust with mothers, because especially for minorities such as immigrants, any little thing that a teacher asks could be regarded as demanding and threatening (Interview, July 31, 2019). Despite being conscious of these majority-minority relationships, the challenges for 
these teachers in becoming agents of welfare are double: they are not only teachers but also part of the majority within the Japanese society.

It is also important to note, however, that immigrant families do not always remain passive. The Filipino children and their mothers also resisted teachers, protesting that they have their own way of living. For example, Mary and Maya could be demonstrating resistance by, respectively, not taking Saki to the hospital and strategically using the concept of "culture."

\section{6-3. Proposal}

The study has demonstrated issues in current "welfare-oriented schools." One of the remarkable issues in the case of Y Elementary School was the fact that most of the practice had been carried out only by the Japanese language teacher and the language supporter, due to lack of commitment by other staff, including the social worker. The social worker visited Y School only once a week and did not have direct contact with immigrant families under X City policy. Consequently, the Japanese language teacher was distressed about her expertise as a teacher. The language supporter also experienced stress when torn between the conflicting demands of school and the immigrant families. Immigrant mothers struggled as well when they could not ask for alternative opinions because they only had limited connections and resources at school.

To overcome those issues and construct effective education-welfare for immigrant children, I propose to implement a school system that ensures immigrant children diverse forms of "welfare" through a variety of faculty members at school. In particular, as a welfare specialist, the social worker can offer "welfare" for immigrant families from different positions. In other words, teachers, language supporters, social workers and other staff can all provide "welfare," but its quality varies depending on the context and the positionalities. For example, the Japanese language teacher provided "welfare" by placing language as an essential tool for building a better parent-child relationship and for surviving in Japan. Education-welfare would be more effective if each teacher and staff member could make use of her own expertise in the spheres of "welfare." Collaboration with the social worker would function better if she could focus on one school and get to know immigrant children well. To sum up, it is necessary to consider what kind of "welfare" each school staff member can provide within the "welfare-oriented school" and how they can collaborate in order to maximize their respective expertise and to secure the lives of immigrant families with the latter's perspectives.

\section{6-4. For Further Research}

This paper is significant as it illustrates the realities within the "welfare-oriented school" and provides immigrants' perspectives on the discussion about education-welfare. The concept of "welfare" can be both "supportive" and "intrusive" depending on the context. Indeed, I should mention that what I saw in the field was only a small part of immigrant children's daily lives, and that my status of student volunteer, interviewer, and "Japanese" affected how immigrant mothers responded to the interviews; for example, they added positive comments about schools after talking about their struggles, worried that I might feel bad because of their previous statements. The fieldwork and interviews, however, made it possible to depict the negotiations of what "welfare" is between teachers and immigrant families in everyday lives. 
In the study, immigrant families often struggled when teachers were involved in their family life in the name of welfare. Their struggle might partly be due to the differences between schools in Japan and the Philippines. For further research, examining how schools in the Philippines are involved in the children's welfare sector is necessary. More specifically, analyzing the Basic Education Act of the Philippines to understand how schools are expected to be involved in the welfare sector and conducting fieldwork at schools to observe the practices would be essential. Through comparison with "welfare-oriented schools" in Japan, immigrant mothers' perspectives would become clearer.

Finally, while this study analyzed welfare for immigrant children at a micro level by focusing on schools, it did not discuss the position of schools among other actors at the macro level. In his theory of welfare regimes, Esping-Andersen (1989) examined the roles of diverse actors such as the government, market, community, and family in welfare. As regards the "welfare-oriented school" in Japan, "schools had no choice" (Kuraishi 2018:40) but to undertake the care roles for children. This paper depicts what is happening within the "welfare-oriented" school, but does not examine the social structure that has forced schools to be involved in the spheres of welfare. In order to grasp the whole picture of what schools can and cannot do in the welfare sector, it is necessary to relativize the role of schools among different actors. By investigating the phenomenon of "welfare-oriented school" at both the micro and macro levels, it will be possible to better envision education-welfare for immigrant children.

\section{References}

Asato, W. (2020). Tayona fukushi regime to kaigaijinzai: 27 Shingata coronavirus to gaikokujin jumin no koyo 2 (Diverse welfare regime and global human resources: The novel coronavirus and the employment of foreign residents 2), Bunkarenjoho (Journal of Japan Culture and Welfare Federation of Agricultural Cooperatives), (508): 58-61. (Japanese)

Esping-Andersen, G. (1989) The Three Worlds of Welfare Capitalism. Cambridge: Polity.

Hara, M. (2018). Shinmitsu-ken no rodo wo ninau JFC (JFC working in the intimate sphere), In Asato, W. (Ed.), Kokusaiido to Shinmitsu-ken (Intimate and Public: Care, Marriage, and Sex), (pp. 159-191). Kyoto: Kyoto University Press. (Japanese)

Ikai, S. (2016). Gyakusanteki realism karano seikatsuhosho (Beyond the Limits of Social Security), Seikatsu keizai seisaku (Journal of the Economic Policy Institute), (234), 5-10. (Japanese)

Japanese Society for the Study of School Social Work. (2008). School Social Workers yosei text (Textbook for the Training of School Social Workers). Tokyo: Chuohoki Publishing. (Japanese)

Johnson, D., Ransom, E., Packwood, T., Bowden, K., and Kogan, M. (1980). Secondary Schools and the Welfare Network. (=1983, T. Iwahashi \& C. Fuku, trans.). Sydney: Allen \& Unwin.

Kaji, I. (2007). Chugoku shusshin seito no shinro kitei yoin (Determinants of Future Course of Chinese Students: Focusing on "Returnees from China" in Osaka), Kyoiku shakaigaku kenkyu (The Journal of Educational Sociology), 80, 331-349. (Japanese)

Kojima, Y. (2016). Gaikokujin no shugaku to fushugaku: Shakaide mienai kodomotachi (Foreign Students' Attendance and Non-Attendance of School: Invisible Children in Society). Osaka: Osaka University Press. (Japanese)

Kuraishi, I. (2014). America kyoikufukushi shakaishi josetsu: visiting teacher to sonojidai (A Social History of Education-Welfare in the United States: The Era of Visiting Teachers). Yokohama: Shumpu Publishing. (Japanese) , (2015). Seikatsu, seizon hosho to kyoiku wo musubumono, hedaterumono: kyoiku fukushi no challenge (Connection and Disconnection between Life Security and Education: The Challenge of Education-Welfare), Kyoikugaku kenkyu (Journal of Education), 82 (4), 571-582. (Japanese)

—, (2018). Seikatsu, seizon hosho no musubinaoshi, sairon: koshi yugo no genjitsu ni do ta- 
chimukauka (Reconsidering the Connection and Disconnection between Life Security and Education: Where does the Convergence of Private and Public Bring Us?), Kyoikugaku kenkyu journal (The Journal of Educational Research), 22: 35-41. (Japanese)

Ministry of Health, Labour, and Welfare (2018a). Setainushi ga gaikokuseki no hihogosha setaisu, setainushi no kokuseki, setaijinin, setairui keibetsu (Number of public assistance recipients whose head of the household is a foreign national, by nationality, number of family members, type of household).https://www.e-stat.go.jp/stat-search/files?page=1\&layout=datalist\&toukei $=00450312 \&$ tst. Last accessed on September 14, 2020. (Japanese)

, (2018b). Fusaino kokusekibetsuni mita nenjibetsu koninkensu, hyakubunritsu (Number of marriages by nationalities for each year). https://www.e-stat.go.jp/dbview?sid=0003214861. Last accessed on September 14, 2020 (Japanese).

Ministry of Internal Affairs and Communications (2017). Heisei 27nen kokusei chosa: shugyo jotai nado kihon shukei (The National Census of 2015: Basic Survey on Employment Status).http:// www.stat.go.jp/data/kokusei/2015/kekka.html. Last accessed on September 14, 2020 (Japanese).

Ministry of Justice (2020). Zairyu gaikokujin tokei: kokuseki chiikibetsu zairyushikaku (zairyumokuteki) betsu airyu gaikokujin (Statistics of Foreign Residents in Japan: by nationalities and purpose of residence). https://www.e-stat.go.jp/stat-search/files?page=1\&layout=datalist\&toukei $=00250012 \&$ tstat $=000001018034 \&$ stat infid $=000032030591$. Last accessed on January 17, 2020. (Japanese)

Nihei, N. (2018). Kyoiku no ronri, muinoronri: seiseiji no henyo no nakade (Logic of "Education" and Logic of "Inactivity": In the Context of Bio-political Transformation), Kyoiku gaku kenkyu journal (The Journal of Educational Research), 22, 43-49. (Japanese)

Ota, H. (2000). Nyukama no kodomo to nihon no gakko (Newcomer Children in Japanese Public Schools). Tokyo: Kokusai Shoin. (Japanese)

Shimizu, K. (Ed.) (2008). Kokowo ikiru newcomer: Osakafuritsu koko ni miru kyoiku shien (Newcomers in High School: Educational Support in Osaka Public High Schools). Tokyo: Akashi Shoten Publishing. (Japanese)

Takada, I. (2019). Wellbeing wo jitsugensuru gakuryoku hosho (Securing education realizes wellbeing: Bridging the education and welfare). Osaka: Osaka University Press. (Japanese)

Yamaguchi, T. and Tsutsumi, T. (2014). Kyoiku to seizonken no kyokai mondai (The border between education and the right of life), In Hirota, A. and Miyadera, A. (Ed.), Kyoiku system to shakai:sono rironteki kento (Education system and society: Theoretical study), (pp.208-226). Yokohama: Seorishobo. (Japanese) 